Int. J. Electrochem. Sci., 13 (2018) 12238 - 12255

International Journal of

ELECTROCHEMICAL

SCIENCE

www.electrochemsci.org

\title{
Effect of Visible Light Illumination on the Atmospheric Corrosion Behaviors of Pure Copper Pre-deposited with NaCl Particles
}

\author{
Xingchen Liu ${ }^{1,2,3}$, Zhuoyuan Chen ${ }^{1,3, *}$, Jian Hou ${ }^{3}$, Jiarun ${ }^{1}{ }^{1}$, Xiaoying Sun $^{1}$, Mingxian Sun ${ }^{3}$ \\ ${ }^{1}$ Key Laboratory of Marine Environmental Corrosion and Bio-fouling, Institute of Oceanology, \\ Chinese Academy of Sciences, 7 Nanhai Road, Qingdao 266071, China \\ ${ }^{2}$ University of Chinese Academy of Sciences, 19 (Jia) Yuquan Road, Beijing 100039, China \\ ${ }^{3}$ State Key Laboratory for Marine Corrosion and Protection, Luoyang Ship Material Research \\ Institute, Wenhai Road, Qingdao 266237, China \\ *E-mail: zychen@qdio.ac.cn
}

doi: $10.20964 / 2018.12 .03$

Received: 16 March 2018 / Accepted: 11 August 2018 / Published: 5 November 2018

\begin{abstract}
Metallic materials serving in the atmospheric environments are usually exposed to solar light illumination. The aim of this work is to determine how the visible light illumination affects the atmospheric corrosion of copper. The mass gains and mass losses after laboratory exposure at different conditions were obtained, and the corrosion morphologies, corrosion products and the electrochemical/photoelectrochemical properties of the corrosion products were analyzed in the present paper. The visible light illumination significantly promoted the atmospheric corrosion of copper. Due to the photoelectrochemical effect, the corrosion products, which possess n-type semiconductor properties, generate the photoinduced electrons and holes. The photoinduced electrons promote the reduction of the dissolved oxygen in the thin $\mathrm{NaCl}$ electrolyte layer on the surface of copper, while the photoinduced holes capture the electrons released from the anodic dissolution of the copper substrate, thus accelerating the atmospheric corrosion process of copper under visible light illumination.
\end{abstract}

Keywords: Atmospheric corrosion; copper; photoelectrochemical effect; photoinduced current density

\section{$\underline{\text { FULL TEXT }}$}

(C) 2018 The Authors. Published by ESG (www.electrochemsci.org). This article is an open access article distributed under the terms and conditions of the Creative Commons Attribution license (http://creativecommons.org/licenses/by/4.0/). 